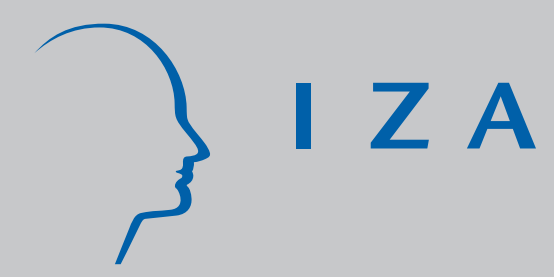

IZA DP No. 498

Individual Rationality and Learning:

Welfare Expectations in East Germany Post-

Reunification

Paul Frijters

J ohn P. Haisken-DeNew

Michael A. Shields

May 2002 


\title{
Individual Rationality and Learning: Welfare Expectations in East Germany Post-Reunification
}

\author{
Paul Frijters \\ Tinbergen Institute, Free University of Amsterdam \\ John P. Haisken-DeNew \\ DIW Berlin and IZA Bonn \\ Michael A. Shields \\ Department of Economics, University of Melbourne and IZA Bonn
}

\author{
Discussion Paper No. 498 \\ May 2002 \\ IZA \\ P.O. Box 7240 \\ D-53072 Bonn \\ Germany \\ Tel.: $+49-228-3894-0$ \\ Fax: +49-228-3894-210 \\ Email: iza@iza.org
}

This Discussion Paper is issued within the framework of IZA's research area Evaluation of Labor Market Policies and Projects. Any opinions expressed here are those of the author(s) and not those of the institute. Research disseminated by IZA may include views on policy, but the institute itself takes no institutional policy positions.

The Institute for the Study of Labor (IZA) in Bonn is a local and virtual international research center and a place of communication between science, politics and business. IZA is an independent, nonprofit limited liability company (Gesellschaft mit beschränkter Haftung) supported by the Deutsche Post AG. The center is associated with the University of Bonn and offers a stimulating research environment through its research networks, research support, and visitors and doctoral programs. IZA engages in (i) original and internationally competitive research in all fields of labor economics, (ii) development of policy concepts, and (iii) dissemination of research results and concepts to the interested public. The current research program deals with (1) mobility and flexibility of labor, (2) internationalization of labor markets, (3) the welfare state and labor markets, (4) labor markets in transition countries, (5) the future of labor, (6) evaluation of labor market policies and projects and (7) general labor economics.

IZA Discussion Papers often represent preliminary work and are circulated to encourage discussion. Citation of such a paper should account for its provisional character. A revised version may be available on the IZA website (www.iza.org) or directly from the author. 
IZA Discussion Paper No. 498

May 2002

\section{ABSTRACT \\ Individual Rationality and Learning: Welfare Expectations in East Germany Post-Reunification}

In this paper we test the Rational Expectations hypothesis using longitudinal data on expectations and realizations of individual welfare for East Germans in the years following reunification. German reunification was unexpected and delivered a large shock to the future prospects of the inhabitants of the former East Germany. We therefore take it as a 'natural' experiment through which to study the rationality of expectations. Our results show that East Germans significantly over-estimated the welfare gains immediately following reunification. The prediction error was largest for the young, the poorly educated and those with children. However, expectations and realizations of life satisfaction in East Germany had converged by 1995, at a level considerably below that of West Germans. We hence conclude that expectations were close to rational after the dust of reunification had settled, but that expectations are not likely to be rational in times of great transition or volatility.

JEL Classification: $\quad \mathrm{C} 23, \mathrm{C} 25, \mathrm{I31}, \mathrm{Z1}$

Keywords: welfare, life satisfaction, rational expectations, learning, German reunification

Michael A. Shields

Department of Economics

University of Melbourne

Victoria 3010

Australia

Phone: +61 383444656

Fax: +61383446899

Email: mshields@melbecon.unimelb.edu.au 


\section{Introduction}

Since its development in the 1960s and 1970s, the Rational Expectations (RE) hypothesis has been a central component of dynamic economic models (Pesaran, 1987; Dominitz and Manski, 1997). This has lead to two empirical questions: i) are expectations rational in the sense that individuals use all information available to them to form unbiased forecasts, and ii) do reported expectations contain useful information for economists about future economic outcomes.

The second of these questions has been answered positively in the last 10 years. Studies using aggregated expectations data in time-series analysis have found expectations to contain information over and above that available in the set of regressors (e.g. Batchelor, 1986; Lee, 1994; Lee and Shields, 2000; Smith and McAleer, 1995). Roberts (1995, 1997) and Mankiw and Reis (2001) hence conclude that macro models perform better in a variety of dimensions when survey-based (inflation) expectations are used in place of constructed model-consistent rational expectations. At the individual level, the usefulness of expectations data has also been clearly confirmed: Flavin (1991), Dominitz (1993) and Alessie and Lusardi (1997), whilst not directly testing the RE hypothesis, each found a positive correlation between individual income expectations and future realizations. This result holds even after controlling for all the other information available to the researcher.

Whether expectations are rational is less clear. Using aggregated data, the results appear mixed. Some studies confirm rationality; others reject it (see Bonham and Cohen 2001 for a review). This ambiguity has stimulated discussion about which type of data could refute the rational expectations hypothesis. Keane and Runkle (1990) and Bonham and Cohen (2001) have argued that an unbiased test of RE can only be achieved by using individual or household level data due to the existence of 'microheterogeneity'. This occurs when individuals use different information sets when making their forecasts, leading to the rejection of the RE hypothesis in aggregate data even if expectations were rational on the individual level. Individual and household longitudinal data, where a great deal of information is known about respondents, allow the direct identification of the types of individuals whose expectations are structurally incorrect.

Most micro-studies so far have rejected rationality. These studies have used individual or household longitudinal data and have focused almost completely on income expectations one year ahead. Dominitz and Manski (1997) used the Survey of Economics Expectations data collected by the University of Wisconsin Survey Center in 1993. They found that forecast errors in income were structural and could be attributed to realized income, age and employment status. Das and van Soest (1999) and Das et al. (1999) investigated the same issue using Dutch household panel data (over the same one-year horizon). Their conclusion was that households do not form their expectations of future 
income rationally, and that households whose income decreased in the past underestimated their future income growth. Souleles (2001) analyzed micro-level data from the Michigan Survey of Consumer Attitudes and Behavior and found that expectations appear to be biased, and that individual forecast error is correlated with demographic characteristics.

In this paper we investigate whether individuals make rational forecasts and learn over time using longitudinal survey data from the German Socio-Economic Panel (GSOEP). We use directly observed expectations realizations of perceived welfare with a five-year time horizon. One advantage of our data is that virtually the whole sample report their welfare expectations and their welfare outcomes. This is not the case with income (see e.g. Das et al. 1999), where sizeable fractions report 'no answer' to either the income expectation question or the actual income question. Because this non-response is aselective, this severely limits the robustness of findings using income expectations. Another advantage is that our welfare question is bounded on a $(0,10)$ scale. This means that outliers will not have large effects, contrary to income questions where income outliers have been shown to have large consequences for the results. ${ }^{1}$ The five-year time horizon in the questions we use implies that expectations require much more thought from the respondents than the one-year time horizon used in income questions. This also makes these forecasts more informative about the expectations process: we expect structural determinants of forecasting ability to come out much more strongly with a longer time horizon.

We test rationality in the aftermath of German reunification. The reunification of East and West Germany is as close to a 'natural' experiment as is experienced in economics: few people anticipated the 'falling of the wall', nor the resulting rapid endowment of a former communist country with a set of market institutions. This means it can be seen as a large exogenous shock, whose aftermath should be very informative about the speed with which individuals adjust their expectations. Furthermore it is the case that the expectations of the East Germans had little impact on the transition policies that the WestGerman government devised for the East. This lack of policy endogeneity makes German reunification an almost ideal case for the study of the reactions of individuals to unexpected large changes in their economic and political environment.

The period immediately following reunification was a time of great optimism for both East and West Germans, even though there was considerable concern about the economic impact of reunification on the West. For East Germans this optimism was reflected in popular slogans such as 'Helmut (Kohl), take us by the hand, lead us to the economic wonderland' (Bach and Trabold, 2000).

\footnotetext{
${ }^{1}$ Income outliers have large effects on actual means of incomes and therefore on the question whether expected and realized means coincide (see Das et al. 1999 for an informative discussion.
} 
Our measure of welfare is the individual's subjective evaluation of their life satisfaction, which is widely accepted by psychologists and a growing number of economists as a good summary statistic for the welfare of an individual (see Bertrand and Mullainthan, 2001; Kahneman et al., 1999; and Oswald, 1997 for discussions). ${ }^{2}$ It is therefore reasonable to suggest that each individual will hold a meaningful expectation about his or her future life satisfaction. To test whether individuals make rational forecasts about their future life satisfaction we construct both continuous and discrete models of the forecast error. These models allow us to identify the type of individuals who make the largest forecast error and to see whether or not individuals learn over time.

The paper is presented as follows. Section II introduces the data that we use, defines the measures of life satisfaction and illustrates the levels of current and expected life satisfaction for East and West Germans in the post-reunification period. The empirical methods by which we examine forecast errors and learning are discussed in Section III. The results are presented in Section IV. Conclusions are drawn in Section V.

\section{Data and Life Satisfaction Profiles following Reunification}

\section{A. Data}

To investigate the rationality of East Germans with regard to their expectations of the welfare (life satisfaction) gains to them from German reunification, we use data from the German Socio-Economic Panel (GSOEP). The GSOEP is a nationally representative panel that has closely followed around 13,500 individuals (living in some 7,000 households) each year since 1984. In 1990, following reunification, the panel was extended to include residents of former East Germany. ${ }^{3}$ The main focus of this paper is the men and women, aged 21-64, who resided in East Germany, which we follow from 1991 up to $1999 .{ }^{4}$ Because our analysis requires individual-specific observations of both expectations (of $t+5$, at $t$ ) and realizations (at $t+5$ ) of life satisfaction we can only use individuals who are observed in the panel for at least a 5-year period. Consequently, there are four possible combinations of expectations and realizations that we observe between 1991 and 1999: 1991-1996; 1992-1997; 1993 1998; and 1994-1999. Out of the 4,100 East German's appearing in the GSOEP between 1991 and

\footnotetext{
${ }^{2}$ The use of life satisfaction responses in cross-sectional and longitudinal surveys, to gain a measure of individual 'utility' and test competing economic theories, is in its infancy. However, a number of recent studies have illustrated the types of questions such data can address. For example, Di Tella et al. (2001) estimated the relative importance of inflation and unemployment in determining respondent's life satisfaction using cross-sectional survey data from the Euro-Barometer Survey Series (1975-1991).

${ }^{3}$ In this paper we use the German version of the GSOEP data (see Haisken-DeNew and Frick, 2000 for details), although the same analysis can be conducted with the international 'scientific use' version, albeit with around 5\% fewer observations.

${ }^{4}$ The question asking GSOEP respondents about their expected life satisfaction was only included since 1991, thus we do not use the 1990 data in this paper.
} 
1999, we observe 2725 individuals over the required duration of 5-years (note that the average duration of respondents in the panel between 1991 and 1999 was 6.4 years). The cases excluded from our econometric analysis are a combination of those who remained in the panel for less than 5 years (attrition) plus those who entered the panel for the first time post-1994. We have checked in detail whether there was any selection on either initial satisfaction levels or expected satisfaction levels, but neither turned out to be the case. Finally, as the data span almost a decade, we have deflated all income information by the OECD main economic indicators consumer price index (base year 1995).

\section{B. Measuring Current and Expected Life Satisfaction}

The dependent variables we use in this analysis are based on two questions asked to each respondent in the GSOEP. These are 'How happy are you are present with your life as a whole?' immediately followed by, 'How happy do you think you will be five years from now?' Both questions are based on the same ordinal scale: running from 0 (very unhappy) to 10 (very happy). Whereas the former question has been included in the West German sample of the GSOEP since 1984, the later question was only added in 1991 into both the East and West samples of the GSOEP. Whilst the determinants of the responses to the first question have been widely examined by economists (see, for example, Clark et al., 2001; Gerlach and Stephan, 1996; and Winkelmann and Winkelmann, 1998), we are unaware of any studies that have looked at the relationship between expectations and realizations of life satisfaction for either East or West Germans.

\section{Current and Expected Life Satisfaction Profiles}

Figures 1 and 2 show the time profiles for current and expected life satisfaction. For comparison, we have also included separate profiles for West Germans (just over 11,000 individuals) over the same period. $^{5}$ A number of interesting patterns emerge. Firstly, current levels of life satisfaction in the East were significantly lower than in the West in every year. Secondly, whilst West Germans experienced a small gradual reduction in their life satisfaction following reunification, East Germans experienced a larger improvement. Consequently, the life satisfaction differential between East and West declined following reunification, but by 1999 a significant differential still remained. Thirdly, expectations of life satisfaction at $t+5$ were far higher than current levels of life satisfaction for East Germans in the first few years following reunification. East Germans appear therefore to have been optimistic about

\footnotetext{
5 Figures 1 and 2: The averaged data points for each year use the full sample of East and West Germans, respectively, observed in the panel between 1991 and 1999 (i.e. 25,903 person-year observations for East Germans and 63,868 personyear observations for West Germans.
} 
the benefits from reunification. Fourthly, the divergence between actual and expected life satisfaction was not evident for West Germans, suggesting that West Germans, on average, were neutral with respect to the anticipated benefits or costs of reunification. Fifthly, actual and expected life satisfaction had converged by 1996 for East Germans.

[FIGURE 1 ABOUT HERE]

[FIGURE 2 ABOUT HERE]

Table 1 illustrates the relationship between expected and realizations of life satisfaction for East and West Germans in more detail. In particular, it is clear that East Germans over-estimated the benefits to them from reunification. For example, in 1991 the expectation of life satisfaction by East Germans for 1996 was 7.31, whilst the mean realization in 1996 was 6.38. This gives a mean forecast error of 0.93 (about 13\%). In the following years the size of the forecast error declined sharply (almost linearly), and by 1994 East Germans were accurately forecasting life satisfaction. In contrast, the forecast error made by West Germans was smaller at about 4\% in 1991, and had disappeared by 1993.

\section{[TABLE 1 ABOUT HERE]}

\section{An Empirical Framework for Testing Individual Rationality and Learning}

Our approach to testing the rationality hypothesis is to examine the determinants of the error between the life satisfaction that individuals expect for time $t+5$ at time $t$ and the actual satisfaction they report at time $t+5$.

\section{A. The Continuous Case}

Following Oswald (1997) and Di Tella et al. (2001), we assume that life satisfaction responses can be treated as a continuous variable. We relax this restriction in the next section. Assuming continuity makes the data informative about whether and how much expectations differ from outcomes because they are directly cardinally comparable. Compare this ability to cardinally compare outcomes and answers with previous research using income expectations and business cycle expectations. Thar reasearch used answers to the question how likely individuals believed that future outcomes would be. These include questions of the form 'what do you think your income will be one year from now: lower/the same/higher') (Keane and Runkle 1990 or Bonham and Cohen 2001). In such cases it is difficult to imply from ex post knowledge of changes in observed income and actual business cycles 
whether expectations were correct or not. For instance, it is not clear what the category 'the same income' means to individuals: Das et al. (1999) found that 'the same income' corresponded to small income increases. They suggest that this means that individuals may have 'the same real income' in mind or 'the same relative income'. Hence the income concept in expectations and realizations may differ in an unknown way. Similar reservations hold for expectations about inflation and business cycles: what an individual perceives as being inflation and a business cycle will for instance depend on her consumption package and her work situation. This perception is furthermore likely to change over time, which makes expectations asked in one period and outcomes in another period difficult to compare. Such comparability problems are not present with our welfare measurements.

As in Table 1, we label the expected level of life satisfaction at $t$ for $t+5$ as $E_{t}\left\{L S_{i, t+5}\right\}$ and the actual level of satisfaction at time $t$ as $L S_{i, t}$. As a first approximation, we suppose the following relation to hold:

$$
L S_{i, t+5}=f\left(x_{i, t}, x_{i, t+5}\right)+v_{i}+\varepsilon_{i t+5}
$$

where $x_{i, t}$ are observable individual characteristics including an intercept; $v_{i}$ is an individual fixed characteristic that can be related to $\mathrm{x}$; and $\varepsilon_{i t}$ a time-varying error-term with unconditional expectation 0 that can be related to $x_{i, t}$ also. This general formulation means we put virtually no structure on the relation between $x_{i, t}$ and $L S_{i, t}$.

We now assume that $E_{t}\left\{L S_{i, t+5}\right\}=L S_{i, t+5}\left(x_{i, t+5}^{e}\right)$ where $x_{i, t+5}^{e}$ is the anticipated $x_{i, t+5}$ by the individual at time $t$. There then holds

$$
E_{t}\left\{L S_{i, t+5}\right\}-L S_{i, t+5}=\left(f\left(x_{i, t}, x_{i, t+5}^{e}\right)-f\left(x_{i, t}, x_{i, t+5}\right)\right)+\left(\varepsilon_{i, t+5}^{e}-\varepsilon_{i, t+5}\right)
$$

which implies that the estimation error has two parts. The part with $\left(f\left(x_{i, t}, x_{i, t+5}^{e}\right)-f\left(x_{i, t}, x_{i, t+5}\right)\right)$ is the part due to anticipation error in observed characteristics $x_{i, t}$ and $\left(\varepsilon_{i, t+5}^{e}-\varepsilon_{i, t+5}\right)$ is due to anticipation error in unobserved characteristics.

We interpret the Rational Expectations hypothesis such that there should be no fundamental predictors of the error in anticipation. Translated to this model, our H0 is that:

$$
\operatorname{Cov}\left\{x_{i, t},\left(f\left(x_{i, t}^{e}, x_{i, t+5}\right)-f\left(x_{i, t}, x_{i, t+5}\right)\right)\right\}=\operatorname{Cov}\left\{x_{i, t},\left(\varepsilon_{i, t+5}^{e}-\varepsilon_{i, t+5}\right)\right\}=0
$$


Under this assumption, we can fit an OLS of $x_{i, t}$ on $E_{t}\left\{L S_{i, t+5}\right\}-L S_{i, t+5}$ where under H0, the coefficients and the intercept should be equal to 0 .

\section{B. The Categorical Case}

We want to check the robustness of these OLS results by relaxing the assumption of continuity of the dependent variables, because the dependent variables are in actuality categorical (ranging 0-10). We then lose the rather convenient ability to simply look at the difference between expectations and outcomes as a cardinal measure of the forecast error. We have to make more specific assumptions about the meaning of expectation answers and outcomes in order to be able to look at the rationality of forecasts.

Many papers using categorical expectations and outcomes have taken expectations to be probabilistic, i.e. have assumed that individuals have a perceived outcome probability distribution (e.g. Mankiw 1990 and Das et al. 1999). In that framework, answers to categorical questions have to be translated to probabilistic statements. One possible assumption is to assume that the stated expected category is the modal category, i.e. the category with the greatest expected probability mass of occurring. By looking at whether the realizations are indeed concentrated in the expected category, this leads to a simple non-parametric test of rationality, though it does not lend itself easily to infer the individual determinants of forecast errors. Another assumption sometimes made is that the stated expected category includes the median of the expected outcome distribution. Rationality can then be tested by noting that when the stated expected category contains the median, one should find less than half of the realizations either below or above the expected category. Again however, such a procedure does not lend itself easily for the identification of the structural determinants of forecast errors. The choice between possible probabilistic interpretations of the expectations questions is also somewhat ad hoc.

In our case, the probabilistic approach is not very useful: the forecast error is so large in our data that the irrationality of expectations shows up trivially under any of the probabilistic assumptions above. This means we, more ambitiously, try to look at the determinants of the forecast error. We therefore, as in the continuous case, assume that individuals' expectation is a point-estimate and that the stated expected category contains that point estimate. This approach makes it possible to look at the determinants of forecast-errors. There is a correspondence with the probabilistic assumptions made in much of the literature though: under the assumptions of our model, our approach can be interpreted as 
corresponding to the assumption that the reported category contains the mean and median of the expectation.

Specifically, assume we have:

$$
\begin{aligned}
& \mathrm{L} S_{i, t}^{*}=x_{i, t-5} \beta_{0}+x_{i, t} \beta_{1}+\varepsilon_{i t} \\
& \mathrm{~L} S_{i, t}=k \Leftrightarrow L S_{i, t}^{*} \in\left[\lambda_{k}, \lambda_{k+1}\right\rangle
\end{aligned}
$$

where $L S_{i, t}^{*}$ is latent life satisfaction; $L S_{i, t}$ is observed satisfaction; and $\lambda_{k}$ is the cut-off point (increasing in $\mathrm{k}$ ) for the satisfaction answers. We do not interpret the coefficients causally, which allows the possibility that $\beta_{0}$ and $\beta_{1}$ include the effect of unobservables related to $x_{i, t-5}$ and $x_{i, t}$. We just assume the residual error term $\varepsilon_{i t}$ to be independent of $x_{i, t-5}$ and $x_{i, t}$ and normally distributed. As normalizations for this ordered-probit model, we set $\lambda_{0}=-\infty, \lambda_{1}=0, \lambda_{11}=+\infty$, and $\operatorname{Var}\left\{\varepsilon_{i t}\right\}=1$.

We now assume that:

$$
E_{t-5}\left\{L S_{i, t}^{*}\right\}=L S_{i, t}^{*}\left(x_{i, t}^{e}\right)=x_{i, t-5} \beta_{0}+x_{i, t} \beta_{1}+\left(x_{i, t}^{e}-x_{i, t}\right) \beta_{1}+\varepsilon^{e}{ }_{i t}+\left(\varepsilon_{i t}-\varepsilon^{e}{ }_{i t}\right)
$$

We translate the RE hypothesis to the $\mathrm{H} 0$ that $x_{i, t-5} \perp\left(x_{i, t}^{e}-x_{i, t}\right),\left(\varepsilon_{i t}-\varepsilon^{e}{ }_{i t}\right)$, i.e. that initial characteristics are orthogonal to forecast errors.

We can now use these assumptions as follows. First, we estimate $\beta_{0}$ and $\beta_{1}$ from an ordered probit on $L S_{i, t}$. By construction, $x_{i, t-5}$ is independent of $L S_{i, t}^{*}-x_{i, t-5} \hat{\beta}_{0}-x_{i, t} \hat{\beta}_{1}$. In turn, this also means that $x_{i, t-5}$ under H0 is independent of $E_{t-5}\left\{L S_{i, t}^{*}\right\}-x_{i, t-5} \hat{\beta}_{0}-x_{i, t} \hat{\beta}_{1}$. This means that if we do an ordered probit of $x_{i, t-5}$ on $E_{t-5}\left\{L S_{i, t}^{*}\right\}-x_{i, t-5} \hat{\beta}_{0}-x_{i, t} \hat{\beta}_{1}$, and set $\lambda_{k}=\hat{\lambda}_{k}$, that under H0, we should find that the coefficient $\hat{\gamma}_{0}^{P R}$ of $x_{i, t-5}$ is zero. If we get something different, this would be direct evidence of structural forecast error. Three methodological points are in order. The first is that the expected estimate of $\beta_{0}$ for the expectation and the outcome is the same even if it only represents a spurious relation with unobservables. This is because the effect of the relation with unobservables is the same under $\mathrm{H} 0$ for both expected satisfaction and actual satisfaction. The second point is that the normalizations are different for the two analyses: the variance of $E_{t-5}\left\{L S_{i, t}^{*}\right\}$ will be higher than 1 because it includes the term $\left(x_{i, t}^{e}-x_{i, t}\right) \hat{\beta}_{1}+\left(\varepsilon_{i t}-\varepsilon^{e}{ }_{i t}\right)$. Hence, assuming that this total error term is again normally distributed, we have to estimate this variance. Thirdly, we note that we would not get the 
same $\hat{\beta}_{1}$ if we included $x_{i, t}$ as a regressor in the ordered probit analysis of expected satisfaction, because it will not be independent of $\left(x_{i, t}^{e}-x_{i, t}\right)$, which is part of the error term.

\section{Specification Testing: OLS vs. Categorical}

In order to be able to judge the added value of the categorical framework, we here develop a test of the equality of the outcomes. We denote the estimated coefficients for $x_{i, t-5}$ of the OLS model of forecast errors by $\hat{\gamma}_{0}^{O L S}$. Our null-hypothesis is that the outcome of the categorical model is the same, i.e.:

$$
\mathrm{H} 0: \quad \gamma_{0}^{P R}=\alpha \hat{\gamma}_{0}^{O L S}
$$

where $\alpha$ is an unknown positive constant that arises because $\hat{\gamma}_{0}^{O L S}$ is estimated under a different normalization than the ordered probit coefficients $\hat{\gamma}_{0}^{P R} \cdot 6$

Under the null hypothesis, we can use the following likelihood ratio test:

$$
2 \mathrm{~L}\left(\hat{\gamma}_{0}^{P R}\right)-2 \mathrm{~L}\left(\alpha \hat{\gamma}_{0}^{O L S}\right) \sim \chi(k)
$$

One practical problem is that $\alpha$ is unknown. To circumvent this, we can note that:

$$
2 \mathrm{~L}\left(\hat{\gamma}_{0}^{P R}\right)-2 \mathrm{~L}\left(\alpha \hat{\gamma}_{0}^{O L S}\right) \geq 2 \mathrm{~L}\left(\hat{\gamma}_{0}^{P R}\right)-\max _{\hat{\alpha}}\left\{2 \mathrm{~L}\left(\hat{\alpha} \hat{\gamma}_{0}^{O L S}\right)\right\}
$$

Hence, by using the $\hat{\alpha}$ that maximizes $\mathrm{L}\left(\hat{\alpha} \hat{\gamma}_{0}^{O L S}\right)$, we get a lower bound for $2 \mathrm{~L}\left(\hat{\gamma}_{0}^{P R}\right)-2 \mathrm{~L}\left(\alpha \hat{\gamma}_{0}^{O L S}\right)$. If we thus find that we can reject the null using $2 \mathrm{~L}\left(\hat{\gamma}_{0}^{P R}\right)-2 \mathrm{~L}\left(\hat{\alpha} \hat{\gamma}_{0}^{O L S}\right)$ as our test statistic, we know that the true statistic will reject the null also.

\section{Explanatory Variables}

The GSOEP contains a wide-range of information about respondents' economic, household and locational characteristics. In this paper one of our principal objectives is to identify the types of individuals who make the largest forecast errors, and conversely to identify those individuals whose forecasts are the most accurate. We follow the recent economics literature (which partly builds upon a

\footnotetext{
${ }^{6} \hat{\gamma}_{0}^{P R}$ is estimated with $\operatorname{var}\left(\varepsilon_{i t}\right)=1$. The OLS model estimates this variance and does not share the same normalization.
} 
long history of life satisfaction research in psychology) that has investigated the economic factors that impact on life satisfaction in our choice of explanatory variables (e.g. Clark et al., 2001; Di Tella et al., 2001; Frey and Stutzer, 2000; Winkelmann and Winkelmann, 1998). Consequently, in the above models we control for the following individual and household characteristics: age (and age-squared), gender, marital status, health status (in terms of disability), number of children, years of schooling, employment status and household income. A priori we might expect that the forecast error will be greatest for the young (with relatively less life experience) and the uneducated (with the lowest learning ability). However, these are conjectures rather than theory-based priors.

Given our focus on German reunification as a 'natural' experiment, we also control for whether or not the individual lives on the border of the East and West, and whether or not she was a member of the Communist Party prior to reunification. In addition, due to the longitudinal nature of the data we also control for a number of recent 'life events'. In particular, an individual's ability to correctly forecast her future life satisfaction may depend (a) whether she has experienced a marital separation or divorce in the last year, (b) whether she has been fired for a job in the last year and (c) whether she moved from the East to the West following reunification. ${ }^{7}$

\section{Results}

\section{A. The Continuous Case}

In Table 2 we show the OLS estimates for the four combinations of expectations and outcomes available, i.e. for $E_{1991}\left\{L S_{i, 1996}\right\}-L S_{i, 1996}$, through till $E_{1994}\left\{L S_{i, 1999}\right\}-L S_{i, 1999}$. For ease of interpreting the intercept, we take the deviations of $x_{i, t}$ from its cross-sectional mean. This allows us to interpret the intercept as the average forecast error.

We see that the average forecast error goes down from about 1 in 1991 to only 0.15 in 1994 . Hence we see a clear convergence of average expectations to realizations. This is the part we can put down to 'population forecast error', i.e. the degree to which everyone had wrong expectations. However, there are clear individual differences in forecast error. The old and more highly educated individuals have a smaller difference between expectations and realizations, which in this case means less absolute forecast error also. What is also interesting is that those living on the border and those having moved to the West from the East following reunification had a much higher expected satisfaction than that which actually materialized. This effect decreased markedly over time however: the degree to which those on

\footnotetext{
${ }^{7}$ We observe 276 individuals who moved from East to West Germany following reunification. To allow for us to estimate the importance of this move in the ability of individuals to accurately forecast their life satisfaction, we have retained them in the East Germany sample.
} 
the border and those having moved to the West were wrong almost disappeared by 1994. It is also clear that individuals with many children were too optimistic in 1991 and beyond.

\section{[TABLE 2 ABOUT HERE]}

The coefficients of just being fired, separated, or divorced, are insignificant and change signs over time. Hence, there is virtually no predictive power in adverse life events at the time of the prediction. Similarly, the coefficients of income, disability level, whether one was a member of the communist party, whether one was married, and gender, are not significant and also often change signs. This means that they also have little predictive power. Finally, the coefficients on employment are interesting, for employment starts off having no effect, but ends up having a large positive significant effect. By construction, this means that the unemployed in 1991 had no different forecast error from others in 1991, but had much lower expectations than outcomes in 1994. The expectations of the unemployed may well have been overly pessimistic in 1994 due to the fact that 1994 was a recession year and 1999 (which is the year the expectations were for) was a boom year in East Germany. Hence, this result may suggest that forecasts were not only wrong after the great transition in 1990, but that they are also wrong over the business cycle for selected groups of individuals as well.

As for the predictive power of individual characteristics, we can see by the declining $R^{2} s$ that individual characteristics explain little of the variance in the data in the later years of the panel.

As a simple decomposition exercise, we can write:

$$
\begin{aligned}
& E\left\{E_{t}\left\{L S_{i, t+5}\right\}-L S_{i, t+5}\right\}^{2}=E\left(\overline{E_{t}\left\{L S_{i, t+5}\right\}}-\overline{L S_{i, t+5}}\right)^{2}+E\left(E_{t}\left\{L S_{i, t+5}\right\}-\overline{E_{t}\left\{L S_{i, t+5}\right\}}\right)^{2} \\
& +E\left(L S_{i, t+5}-\overline{L S_{i, t+5}}\right)^{2}-\operatorname{Cov}\left(E_{t}\left\{L S_{i, t+5}\right\}, L S_{i, t+5}\right)
\end{aligned}
$$

This decomposes the square forecast error into the square average forecast error, the variance in forecast, the variance in realizations and the covariance. For the four periods, this decomposition reads:

$$
\begin{aligned}
& E\left\{E_{1991}\left\{L S_{i, 1996}\right\}-L S_{i, 1996}\right\}^{2}=5.25=0.99+2.89+3.19-1.82 \\
& E\left\{E_{1992}\left\{L S_{i, 1997}\right\}-L S_{i, 1997}\right\}^{2}=4.83=0.51+2.75+3.27-1.70 \\
& E\left\{E_{1993}\left\{L S_{i, 1998}\right\}-L S_{i, 1998}\right\}^{2}=4.64=0.19+2.90+3.65-2.10 \\
& E\left\{E_{1994}\left\{L S_{i, 1999}\right\}-L S_{i, 1999}\right\}^{2}=4.12=0.02+2.96+3.58-2.44
\end{aligned}
$$

Three items of interest stand out here: again we see the disappearance of the 'population forecast error' $\left(=E\left(\overline{E_{t}\left\{L S_{i, t+5}\right\}}-\overline{L S_{i, t+5}}\right)^{2}\right)$. We also see that the contribution of the population forecast error to the total 
squared error in 1991 was about $20 \%$. Comparing this with the approximately $2 \%$ that all the individual characteristics combined contributed to the explanation of $E\left\{E_{t}\left\{L S_{i, t+5}\right\}-L S_{i, t+5}\right\}^{2}$, we can conclude that the importance of individual characteristics compared to population characteristics in the forecast error is almost negligible. This would indicate that expectations are indeed, on average, 'roughly right' apart from a bias shared by all individuals. Lastly, we see an increasing $\operatorname{Cov}\left(E_{t}\left\{L S_{i, t+5}\right\}, L S_{i, t+5}\right)$. This covariance essentially denotes the ability of individuals to predict their future satisfaction, which apparently increased over the years following reunification. We interpret this as an indication that learning has taken place in this period.

Summarizing, the results from our models suggest the major part of the forecast errors made by East Germans in the immediate years following reunification was general to the entire population. However, those with higher education, higher age and those not living on the border or having moved from the East to the West had the smallest forecast error. Many of the individual predictors of the forecast error in 1991 had become insignificant by 1994, as had the average forecast error. Our East German sample also experienced a fairly rapid increase (within four years) in their ability to correctly predict their future life satisfaction.

\section{B. The Categorical Case}

The results of the estimation procedure for the pooled ordered probit specification are provided in Table 3. For direct comparison, we also include results for a pooled (1991-1999) OLS model (the continuous case). Importantly, the results are very similar to those presented in Table 2, even though we are now pooling over the four sets of years. From the ordered probit model we can see that expectations in 1991 for life satisfaction in 1996 are on average wrong by about 0.75 points $(=0.44+$ $(1991-\overline{y e a r}) *-0.205)$, and only by 0.15 in 1994.

\section{[TABLE 3 ABOUT HERE]}

The test statistic for equality of the OLS and the probit coefficients is 8.6, which is an underbound for the true test statistic. The $1 \%$ critical value of the corresponding Chi-square distribution for 17 degrees of freedom is 33.4. The $10 \%$ critical value of the Chi-square distribution for 17 degrees of freedom is 24.8. Hence, the null of equal coefficients cannot be rejected for any reasonable level of significance. This fits previous findings that a categorical analysis of life satisfaction leads to similar results as continuous analysis (e.g. Di Tela et al. 2001). It is also remarkable because the probit results 
required much stronger functional assumptions of error-terms. These apparently are not important for the issue at hand. Again we see that the older and more educated have lower prediction errors. The employed, those on the border and those having moved to the West have higher prediction errors. The estimated standard deviation of 1.195 , corresponding to a variance of 1.43 , suggests that compared to actual satisfaction error, the forecast error term $\left(x_{i, t}^{e}-x_{i, t}\right) \hat{\beta}_{1}+\left(\varepsilon_{i t}-\varepsilon^{e}{ }_{i t}\right)$ adds another $43 \%$ variance, which does not seem implausible.

\section{Conclusion}

In this paper we have provided a novel test of individual rationality and learning by using longitudinal data on current $(t)$ and expected $(t+5)$ welfare for East German's in the years following reunification. Our data is drawn from the German Socio-Economic Panel (GSOEP), and shows that whilst current levels of life satisfaction in East Germany immediately following reunification were considerably lower than the levels experienced by their West German counterparts, expectations of life satisfaction five-years hence were high. Interestingly, the average expected life satisfaction for East Germans in 1996, predicted in 1991, was at a level roughly equivalent to actual life satisfaction in West Germany in 1991. Clearly, expectations of the benefits from reunification were high in the East, with East Germans having a 'reasonably' good idea of the level of life satisfaction experienced in the West.

Both continuous and categorical models clearly reject rationality in expectations formation over the five-year time horizon that we have examined. We find strong evidence of micro-heterogeneity in the sense of Bonham and Cohen (2001): the uneducated, the young and those with children had structurally higher forecast errors. However, these individual characteristics explained only a small component of the total forecast error, with the vast part of the forecast errors made by East Germans in the immediate years following reunification being general to the entire population. Moreover, many of the individual predictors of the forecast error in 1991 had become insignificant by 1994, as had the average forecast error. It appears that virtually all East Germans experienced a fairly rapid increase (within four years) in their ability to correctly predict their future life satisfaction. The results therefore indicate that learning about the aggregate shocks took place over this period and that expectations were close to rational in the period 1994-1999. The broader implications are that the assumption of rationality does not appear too bad in 'normal' times, but that it appears inappropriate in times of great transition. 
FIGURE 1:

Average Current $(t)$ and Expected $(t+5)$ Life Satisfaction for East Germans following Reunification

— Average Current Life Satisfaction - - - Average Expected Life Satisfaction

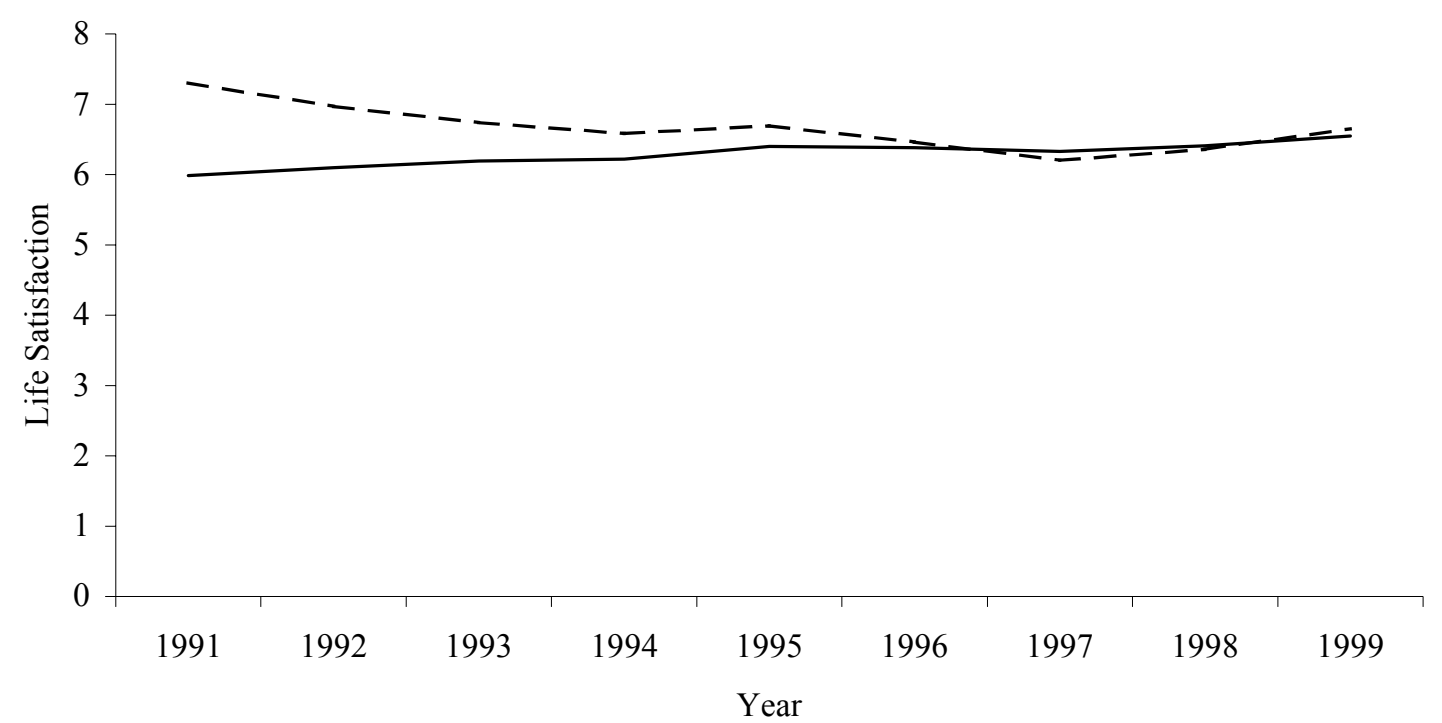

FIGURE 2:

Average Current $(t)$ and Expected $(t+5)$ Life Satisfaction for West Germans following Reunification

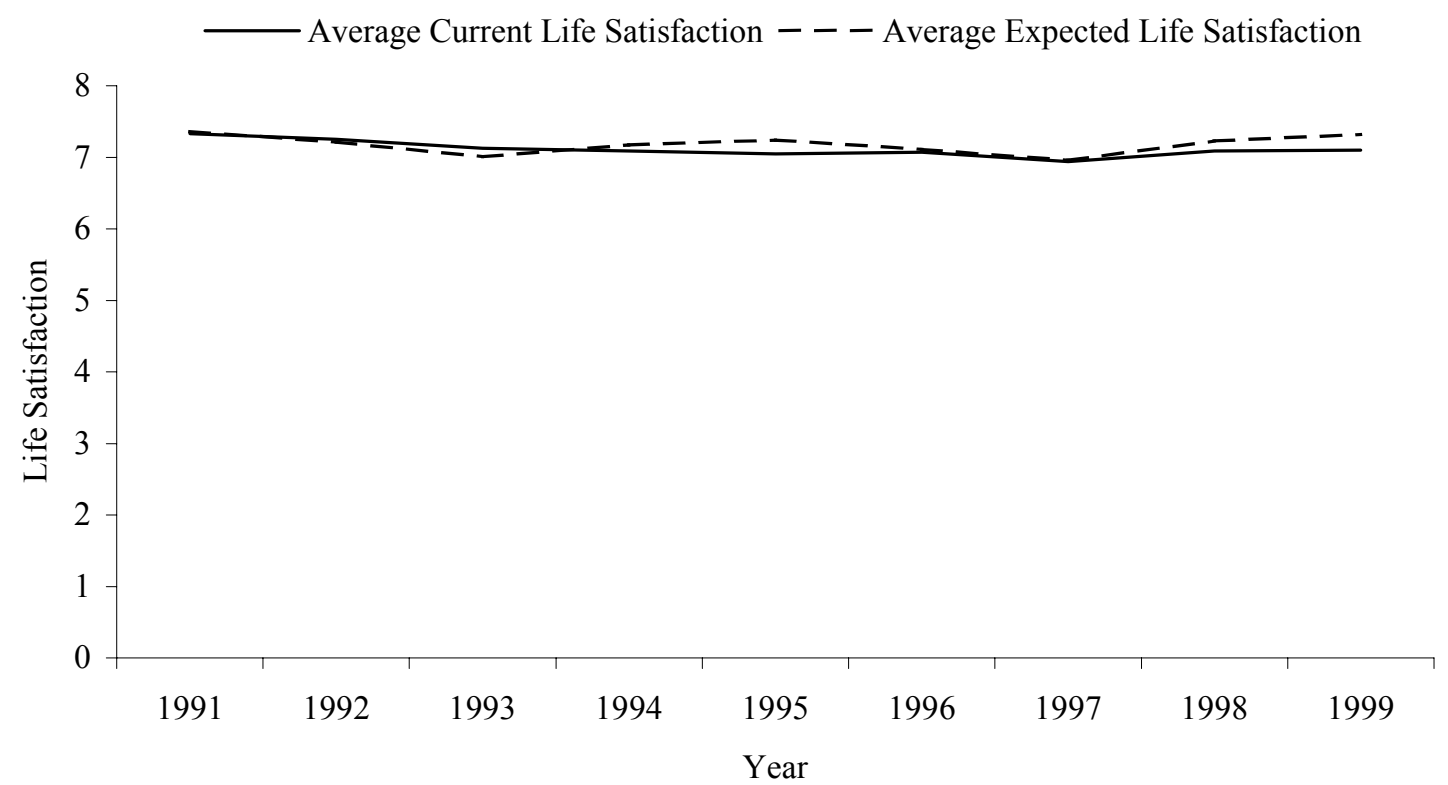


TABLE 1

Expectations, Realizations and the Mean Forecast Error for East and West Germans

\begin{tabular}{l|ccc|ccc}
\hline & \multicolumn{3}{|c|}{ EAST } & \multicolumn{2}{c}{ WEST } \\
\hline & $E_{t}\left\{L S_{i, t+5}\right\}$ & $\overline{L S}_{i, t+5}$ & $E_{t}\left\{L S_{i, t+5}\right\}-\overline{L S}_{i, t+5}$ & $E_{t}\left\{L S_{i, t+5}\right\}$ & $\overline{L S}_{i, t+5}$ & $E_{t}\left\{L S_{i, t+5}\right\}-\overline{L S} \bar{L}_{i, t+5}$ \\
\hline \multirow{3}{*}{$1991-6$} & & & & & \\
$1992-7$ & 7.31 & 6.38 & 0.93 & 7.36 & 7.07 & 0.29 \\
$1993-8$ & 6.97 & 6.33 & 0.64 & 7.21 & 6.94 & 0.27 \\
$1994-9$ & 6.74 & 6.41 & 0.33 & 7.01 & 6.94 & -0.08 \\
\hline
\end{tabular}

Notes: $E_{t}\left\{L S_{i, t+5}\right\}$ is the expected level of life satisfaction at $t$ for $t+5 . \overline{L S}_{i, t+5}$ is the realized level of life satisfaction at $t+5$.

$E_{t}\left\{L S_{i, t+5}\right\}-\overline{L S}_{i, t+5}$ is the mean forecast error. 
TABLE 2

OLS Estimates of the Forecast Error:

Expected Life Satisfaction $(t+5)$ minus Actual Life Satisfaction $(t+5)$

Conditional on Individual Characteristic $(t)$

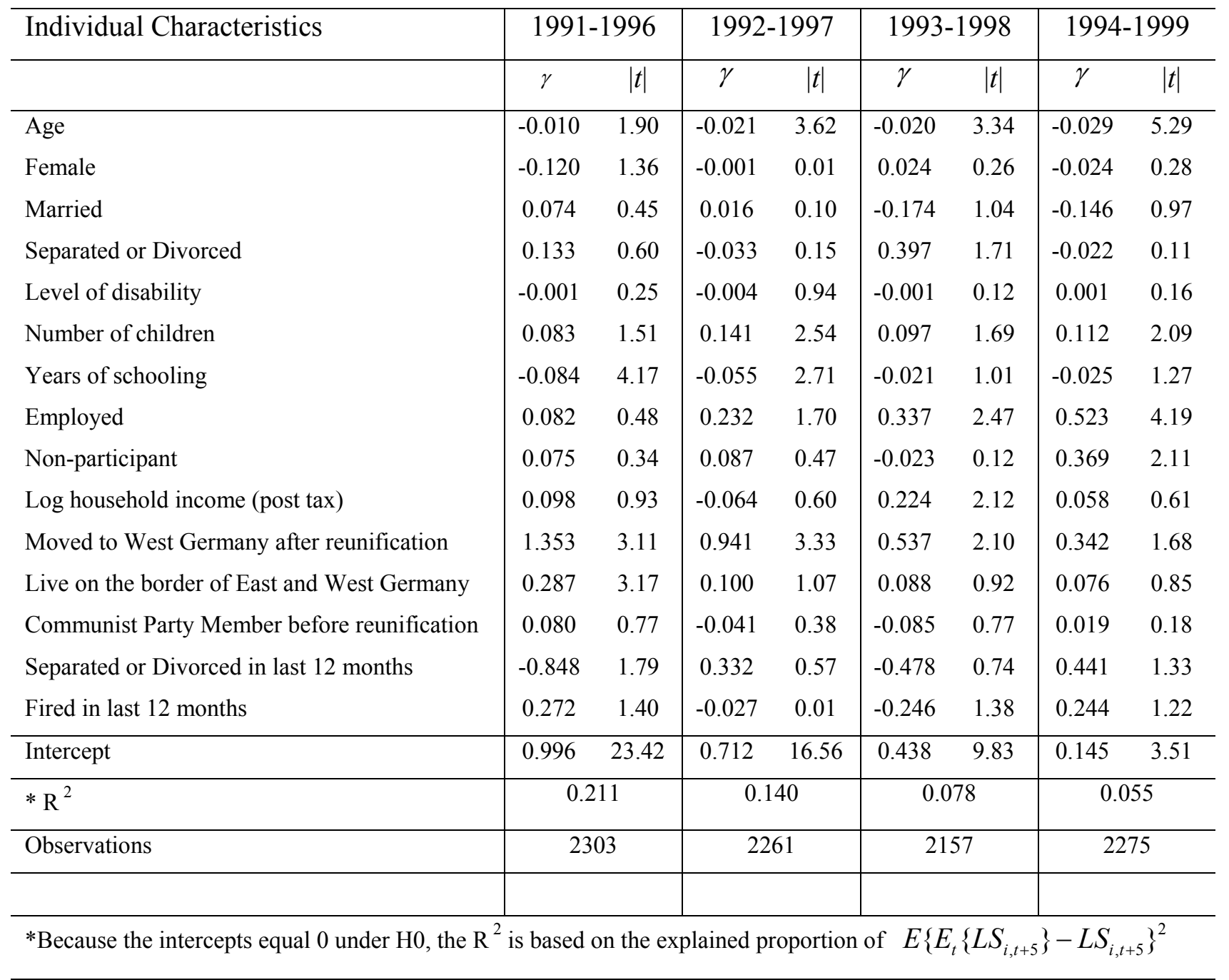


TABLE 3

Pooled OLS and Ordered Probit Estimates of the Forecast Error:

Expected Life Satisfaction $(t+5)$ minus Actual Life Satisfaction $(t+5)$

Conditional on Individual Characteristic $(t)$

\begin{tabular}{|c|c|c|c|c|}
\hline \multirow[t]{3}{*}{ Individual Characteristics } & \multicolumn{2}{|c|}{ OLS } & \multicolumn{2}{|c|}{ ORDERED PROBIT } \\
\hline & \multicolumn{2}{|c|}{ 1991-1999 } & \multicolumn{2}{|c|}{ 1991-1999 } \\
\hline & $\hat{\gamma}_{0}^{O L S}$ & $|t|$ & $\hat{\gamma}_{0}^{P R}$ & $|t|$ \\
\hline Age & -0.020 & 7.16 & -0.014 & 8.42 \\
\hline Female & -0.031 & 0.69 & -0.015 & 0.54 \\
\hline Married & -0.064 & 0.79 & -0.032 & 0.66 \\
\hline Separated or Divorced & 0.094 & 0.86 & 0.070 & 1.06 \\
\hline Level of disability & -0.001 & 0.44 & -0.001 & 0.82 \\
\hline Number of children & 0.103 & 3.72 & 0.054 & 3.24 \\
\hline Years of schooling & -0.047 & 4.62 & -0.033 & 5.37 \\
\hline Employed & 0.311 & 4.47 & 0.205 & 4.94 \\
\hline Non-participant & 0.144 & 1.53 & 0.116 & 2.06 \\
\hline Log household income (post tax) & 0.083 & 1.62 & 0.073 & 2.35 \\
\hline Moved to West Germany after reunification & 0.662 & 4.99 & 0.531 & 6.63 \\
\hline Live on the border of East and West Germany & 0.139 & 3.01 & 0.095 & 3.44 \\
\hline Communist Party Member before reunification & -0.015 & 0.28 & -0.045 & 1.42 \\
\hline Separated or Divorced in last 12 months & 0.030 & 0.13 & -0.003 & 0.03 \\
\hline Fired in last 12 months & 0.051 & 0.48 & 0.022 & 0.42 \\
\hline Year & -0.283 & 14.30 & -0.205 & 17.34 \\
\hline Intercept & 0.576 & 26.77 & 0.444 & 34.55 \\
\hline $\mathrm{R}^{2}$ & \multicolumn{2}{|c|}{0.100} & \multicolumn{2}{|c|}{ NA } \\
\hline Mean log-likelihood & \multicolumn{2}{|c|}{ NA } & \multicolumn{2}{|c|}{1.924} \\
\hline$\chi^{2}$ Test of parameter equality (d.f. 17) & \multicolumn{2}{|c|}{ NA } & \multicolumn{2}{|c|}{8.636} \\
\hline$\hat{\alpha}$ & & & \multicolumn{2}{|c|}{0.742} \\
\hline Observations & \multicolumn{2}{|c|}{8996} & \multicolumn{2}{|c|}{8996} \\
\hline
\end{tabular}




\section{References}

Alessie, R., Lusardi, A. (1997). Saving and income smoothing: Evidence from panel data. European Economic Review, 41, 1251-1279.

Bach, S., Trabold, H. (2000). Ten years after German monetary, economic and social union: An introduction. Quarterly Journal of Economic Research, 2, 149-151.

Batchelor, R. (1986). Quantitative v. qualitative measures of inflation expectations. Oxford Bulletin of Economics and Statistics, 48, 99-120.

Bertrand, M., Mullainthan, S. (2001). Do people mean what they say? Implications for subjective survey data. American Economic Review, Papers and Proceedings, 91, 67-72.

Bonham, C., Cohen, R. (2001). To aggregate, pool, or neither: Testing the Rational Expectations Hypothesis using survey data. Journal of Business and Economic Statistics, 19, 278-291.

Clark, A., Georgellis, Y., Sanfrey, P. (2001). Scarring: the psychological impact of past unemployment. Economica, 68, 221-241.

Das, M., van Soest, A. (1999). A panel data model for subjective information on household income growth. Journal of Economic Behavior and Organization, 40, 409-426.

Das, M., Dominitz, J., van Soest, A. (1999). Comparing predictions and outcomes: Theory and application to income changes. Journal of the American Statistical Association, 94, 75-90.

Di Tella, R., MacCulloch, R. and Oswald, A. (2001). Preferences over inflation and unemployment: Evidence from surveys of happiness. American Economic Review, 91, 335-341.

Dominitz, J. (1993). Subjective expectations of unemployment, earnings and income. University of Wisconsin-Madison Working Paper, November.

Dominitz, J., Manski, C. (1997). Using expectations data to study subjective income expectations. Journal of the American Statistical Association, 92, 855-872.

Flavin, M. (1991). The joint consumption/assets demand decision: A case study in robust estimation. NBER Working Paper no. 3802.

Frey, B., Stutzer, A. (2000). Happiness, economy and institutions. Economic Journal, 110, 918-938.

Gerlach, K., Stephan, G. (1996). A paper on unhappiness and unemployment in Germany. Economics Letters, 52, 325-330.

Haisken-DeNew, J. and Frick, J. (2000). Desktop companion to the German Socio-Economic Panel Study (GSOEP). German Institute for Economic Research: Berlin.

Kahneman, D., Diener, E., Schwarz, N. (1999, Eds), Foundations of Hedonic Psychology: Scientific Perspectives on Enjoyment and Suffering. New York: Russel Sage Foundation. 
Keane, M., Runkel, D. (1990). Testing for rationality of price forecasts: New evidence from panel data. American Economic Review, 80, 714-735.

Lee, K. (1994). Formation of Price and Cost Inflation Expectations in British Manufacturing: A Multisectoral Analysis. Economic Journal, 104, 372-385.

Lee, K., Shields, K. (2000). Expectations formation and business cycle fluctuations: An analysis of actual and expected output in UK manufacturing industries, 1975-1993. Oxford Bulletin of Economics and Statistics, 62, 463-490.

Lovell, M. (1986). Tests of the Rational Expectations Hypothesis. American Economic Review, 76, $110-124$.

Manski C. (1990), 'The use of intentions data to predict behavior: best-case analysis', Journal of the American Statistical Association, 85, 934-940.

Mankiw, G., Reis, R. (2001). Sticky information versus sticky prices: A proposal to replace the new Keynesian Phillips curve. NBER Working Paper no. 8290.

Oswald, A. (1997). Happiness and economic performance. Economic Journal, 107, 1815-1831.

Pesaran, H. (1987). The Limits of Rational Expectations. Oxford: Basil Blackwell.

Roberts, J. (1995). New Keynesian economics and the Phillips curve. Journal of Money, Credit and Banking, 27, 975-984.

Roberts, J. (1997). Is inflation sticky? Journal of Monetary Economics, 173-196.

Smith, J., McAleer, M. (1995). Alternative procedures for converting qualitative response data to quantitative expectations: An application to Australian manufacturing. Journal of Applied Econometrics, 10, 165-186.

Souleles, N. (2001). Consumer sentiment: Its rationality and usefulness in forecasting expenditure Evidence from the Michigan micro data. Mimeo, Finance Department, University of Pennsylvania.

Winkelmann, L., Winkelmann, R. (1998). Why are the unemployed so unhappy? Evidence from panel data. Economica, 65, 1-17. 


\section{IZA Discussion Papers}

$\begin{array}{cl}\text { No. } & \text { Author(s) } \\ 482 & \begin{array}{l}\text { P. Kuhn } \\ \text { C. Weinberger }\end{array} \\ 483 & \begin{array}{l}\text { H. Rapoport } \\ \text { A. Weiss }\end{array} \\ & \\ 484 & \text { J. H. Bishop } \\ & \text { L. Woessmann } \\ 485 & \text { L. Woessmann } \\ & \text { M. R. West }\end{array}$

\section{J. T. Addison}

L. Bellmann

C. Schnabel

J. Wagner
A. L. Booth
M. L. Bryan
R. L. Lumsdaine
E. S. Prasad
A. Ciccone
G. Peri
D. Del Boca
S. Pasqua

R. Rotte

C. M. Schmidt

\section{R. Lalive}

J. Zweimüller

R. M. Leontaridi

M. E. Ward

J. Wagner

R. Sternberg
Title

Leadership Skills and Wages

In-Group Cooperation in a Hostile Environment: An Economic Perspective on Some Aspects of Jewish Life in (Pre-Modern) Diaspora

Institutional Effects in a Simple Model of Educational Production

Class-Size Effects in School Systems Around the World: Evidence from Between-Grade Variation in TIMSS

Who pays for General Training? New Evidence for British Men and Women

Identifying the Common Component of International Economic Fluctuations:

A New Approach

Identifying Human Capital Externalities:

Theory with an Application to US Cities

Employment Patterns of Husbands and Wives and Family Income Distribution in Italy (19771998)

Social Security and Taxation of Labour Subject to Subsidiarity and Freedom of Movement

On the Production of Victory: Empirical Determinants of Battlefield Success in Modern War

Benefit Entitlement and Unemployment Duration: The Role of Policy Endogeneity

Work-Related Stress, Quitting Intentions and Absenteeism

The Role of the Regional Milieu for the Decision to Start a New Firm: Empirical Evidence for Germany

German Works Councils Old and New: Incidence, Coverage and Determinants

Changes in the Structure of Earnings During the 4 Polish Transition

European Integration and Employment:

A New Role for Active Fiscal Policies?

Individual Rationality and Learning: Welfare

J. P. Haisken-DeNew

M. A. Shields
Expectations in East Germany Post-

Reunification
Area

Date

6

04/02

04/02

04/02

5

$04 / 02$

$04 / 02$

$04 / 02$

04/02

04/02

05/02

05/02

05/02

05/02

05/02

05/02 